Photochemical \&
Photobiological Sciences

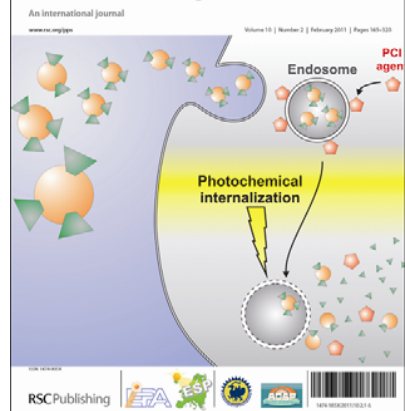

Perspectives

Photodynamic therapy enhancement of antitumor immunity

C. M. Brackett and S. O. Gollnick, Photochem.

Photobiol. Sci., 2011, 10, 649

PDT-induced inflammatory and host

responses

M. Firczuk, D. Nowis and J. Gołą, Photochem.

Photobiol. Sci., 2011, 10, 653

Cancer vaccines generated by photodynamic therapy

M. Korbelik, Photochem. Photobiol. Sci., 2011, 10, 664

DAMPs and PDT-mediated photo-oxidative stress: exploring the unknown

A. D. Garg, D. V. Krysko, P. Vandenabeele and P. Agostinis, Photochem. Photobiol. Sci., 2011, 10, 670

Antitumor immunity promoted by vascular occluding therapy: lessons from vasculartargeted photodynamic therapy (VTP)

D. Preise, A. Scherz and Y. Salomon, Photochem.

Photobiol. Sci., 2011, 10, 681

On the cutting edge: protease-sensitive prodrugs for the delivery of photoactive compounds

D. Gabriel, M. F. Zuluaga and N. Lange, Photochem. Photobiol. Sci., 2011, 10, 689

Combination of photodynamic therapy and immunomodulation for skin diseases-update of clinical aspects

X.-L. Wang, H.-W. Wang, K.-H. Yuan, F.-L. Li and Z. Huang, Photochem. Photobiol. Sci., 2011, 10, 704

Nanoparticles: their potential use in antibacterial photodynamic therapy S. Perni, P. Prokopovich, J. Pratten, I. P. Parkin and M. Wilson, Photochem. Photobiol. Sci., 2011, 10, 712

Photosensitiser-antibody conjugates for photodynamic therapy

A. J. Bullous, C. M. A. Alonso and R. W. Boyle, Photochem. Photobiol. Sci., 2011, 10, 721

The immunosuppressive side of PDT

P. Mroz and M. R. Hamblin, Photochem.

Photobiol. Sci., 2011, 10, 751
Synthetic approaches for the conjugation of porphyrins and related macrocycles to peptides and proteins

F. Giuntini, C. M. A. Alonso and R. W. Boyle, Photochem. Photobiol. Sci., 2011, 10, 792

Combination approaches to potentiate immune response after photodynamic therapy for cancer

T. G. St. Denis, K. Aziz, A. A. Waheed, Y.-Y. Huang, S. K. Sharma, P. Mroz and M. R. Hamblin, Photochem. Photobiol. Sci., 2011, 10, 802

Clinical and immunolgical response to photodynamic therapy in the treatment of vulval intrepithelial neoplasia

S. Daayana, U. Winters, P. L. Stern and H. C. Kitchener, Photochem. Photobiol. Sci., 2011, 10, 810

Papers

Cytosolic delivery of LDL nanoparticle cargo using photochemical internalization H. Jin, J. F. Lovell, J. Chen, K. Ng, W. Cao, L. Ding, Z. Zhang and G. Zheng, Photochem. Photobiol. Sci., 2011, 10, 817

Preliminary safety and efficacy results of laser immunotherapy for the treatment of metastatic breast cancer patients

X. Li, G. L. Ferrel, M. C. Guerra, T. Hode, J. A. Lunn, O. Adalsteinsson, R. E. Nordquist, H. Liu and W. R. Chen, Photochem. Photobiol. Sci., 2011, 10, 822

Targeted photodynamic therapy of breast cancer cells using antibody-phthalocyaninegold nanoparticle conjugates

T. Stuchinskaya, M. Moreno, M. J. Cook, D. R. Edwards and D. A. Russell, Photochem.

Photobiol. Sci., 2011, 10, 832

Methylene blue covalently loaded polyacrylamide nanoparticles for enhanced tumor-targeted photodynamic therapy M. Qin, H. J. Hah, G. Kim, G. Nie, Y.-E. Koo Lee and R. Kopelman, Photochem. Photobiol. Sci., 2011, 10, 842

Quantum dot-folic acid conjugates as potential photosensitizers in photodynamic therapy of cancer

V. Morosini, T. Bastogne, C. Frochot, R.

Schneider, A. François, F. Guillemin and M.

Barberi-Heyob, Photochem. Photobiol. Sci., 2011, 10, 852 


\title{
Targeted photodynamic therapy of breast cancer cells using antibody-phthalocyanine-gold nanoparticle conjugates $\uparrow$
}

\author{
Tanya Stuchinskaya, ${ }^{a}$ Miguel Moreno, ${ }^{a}$ Michael J. Cook, ${ }^{a}$ Dylan R. Edwards ${ }^{b}$ and David A. Russell $* a$ \\ Received 11th January 2011, Accepted 7th March 2011 \\ DOI: $10.1039 / \mathrm{c} 1 \mathrm{pp05014a}$
}

\begin{abstract}
A 4-component antibody-phthalocyanine-polyethylene glycol-gold nanoparticle conjugate is described for use as a potential drug for targeted photodynamic cancer therapy. Gold nanoparticles $(4 \mathrm{~nm})$ were stabilised with a self-assembled layer of a zinc-phthalocyanine derivative (photosensitiser) and a heterobifunctional polyethylene glycol. Anti-HER 2 monoclonal antibodies were covalently bound to the nanoparticles via a terminal carboxy moiety on the polyethylene glycol. The nanoparticle conjugates were stable towards aggregation, and under irradiation with visible red light efficiently produced cytotoxic singlet oxygen. Cellular experiments demonstrated that the nanoparticle conjugates selectively target breast cancer cells that overexpress the HER2 epidermal growth factor cell surface receptor, and that they are effective photodynamic therapy agents.
\end{abstract}

\section{Introduction}

There has been a growing interest in the use of gold nanoparticles in biomedical research due to a combination of unique properties. Such nanoparticles show good biocompatibility as they are generally considered to be benign, ${ }^{1}$ possess a high surface area and are characterised by facile surface functionalisation through selfassembly of thiolates on the gold surface via formation of a $\mathrm{Au}-\mathrm{S}$ bond. ${ }^{2,3}$ It has been demonstrated that gold nanoparticles can be used as efficient drug delivery vehicles both in cancer diagnostics, e.g., intracellular imaging, and in cancer therapy. ${ }^{1,4}$

For anti-cancer therapy, molecular recognition towards specific cell surface receptors can be achieved by conjugation with an antibody. A number of studies have shown that gold nanoparticles conjugated with antibodies are efficient in targeting and then can destroy cancerous tissue by conversion of near-infrared irradiation into heat. ${ }^{1,5,6}$ Gold nanostructures, including nanocages, ${ }^{5}$ nanorods $^{6}$ and nanoshells, ${ }^{7}$ have all served as photothermal therapeutic agents following illumination with light of wavelengths between 700-800 nm. Typical 'spherical' gold nanoparticles of $c a$. $16 \mathrm{~nm}$ have a surface plasmon absorption maximum around 514 $520 \mathrm{~nm}$. However, structural modification of the gold nanostructures during synthesis provides a shift of the absorption band to the desirable 'therapeutic window' of $650-900 \mathrm{~nm}$, i.e., the near-infrared region where blood and soft tissue are relatively transparent. ${ }^{5-7}$ In photothermal experiments, gold nanoparticles with anti-VEGF antibodies adsorbed on the surface proved to be

${ }^{a}$ School of Chemistry, University of East Anglia, Norwich, Norfolk, NR4 7TJ,UK.E-mail:d.russell@uea.ac.uk

${ }^{b}$ School of Biological Sciences, University of East Anglia, Norwich, Norfolk, NR4 7TJ, UK

$\dagger$ This article is published as part of a themed issue on immunological aspects and drug delivery technologies in PDT. more efficient for the induction of apoptosis in $\beta$-chronic lymphocytic leukemia cells as compared to gold nanoparticles without antibodies. ${ }^{8}$ Disadvantages of photothermal cancer treatment can be the high power density of irradiation of up to $35 \mathrm{~J} \mathrm{~cm}^{-2}$ and a poor selectivity, as both normal and tumour cells can be destroyed in the path of the laser light. ${ }^{9}$ However, it has been also reported that specifically designed gold nanocages as well as agglomerated spherical gold nanoparticles can induce cancer cell death at a power as low as $1.5 \mathrm{~J} \mathrm{~cm}^{-2}$ using short-pulse irradiation with a femtosecond laser., 5

In photodynamic therapy (PDT) of cancer, irradiation with visible and/or near-infrared light leads to activation of a photosensitiser drug. Upon illumination, the photosensitiser generates reactive oxygen species, which in turn react rapidly with biological substrates, initiating an apoptotic or necrotic response and eventually leading to oxidative damage and cell death. $\cdot^{10-12}$ Since the light is specifically chosen to coincide with the maximum absorption wavelength of the photosensitiser, initial damage following PDT is limited to the site of concentration of the photosensitiser drug molecule without destruction of healthy tissue. ${ }^{4}$

Among some of the promising second-generation photosensitisers are phthalocyanines $(\mathrm{Pc})$, which have a strong absorption band in the far-red region of the visible spectrum $\left(\lambda_{\max }=c a\right.$. $680 \mathrm{~nm}$ ) and can efficiently absorb light (Pc molar extinction coefficient $\left.(\varepsilon)=c a \cdot 10^{5} \mathrm{M}^{-1} \mathrm{~cm}^{-1}\right) \cdot{ }^{11}$ The efficacy of phthalocyanine derivatives as a photosensitiser can be significantly enhanced by attachment to the surface of gold nanoparticles. We have previously shown that the surface-bound $\mathrm{Zn}$ (II) phthalocyanine derivative $(\mathrm{C} 11 \mathrm{Pc})$ exhibits a remarkable enhancement of the singlet oxygen quantum yield in the presence of an associated phase transfer reagent, tetraoctylammonium bromide. ${ }^{13,14}$ This enhancement in singlet oxygen generation is possibly due to the phase transfer agent stabilising an active monomeric form 
of the photosensitiser. Cellular experiments using the HeLa cervical cancer cell line demonstrated that irradiation of the conjugates within the cells causes high cell mortality through the photodynamic effect. ${ }^{13}$ An extensive photodynamic effect using the C11Pc nanoparticle conjugates has been demonstrated recently in vivo where a significant decrease in the rate of growth of a subcutaneously implanted amelanotic melanoma tumour was observed. ${ }^{15}$ Similarly, experiments on 5RP7 rat fibroblasts cancer cells showed promising results in vivo by suppressing the tumour growth after treatment with zinc phthalocyanine-loaded singlewall carbon nanohorns. ${ }^{16}$

Incorporation of cell-targeting peptides or antibodies onto the nanoparticle surface is highly desirable for therapeutic applications, as it would enable selective cell and/or nuclear targeting. Direct physisorption of fluorescently tagged antibodies to the surface of gold nanoparticles has been used for some time to produce 'immunogold'. However, such simple methods of nanoparticle functionalisation results in poor orientation of the recognition component (the $\mathrm{F}(\mathrm{ab})_{2}$ region) of the antibody, nonspecific binding of the nanoparticle conjugates and agglomeration of small gold nanoparticles. ${ }^{17}$ These drawbacks can be overcome by modification of the nanoparticle's surface with polyethylene glycol (PEG), which has been approved for human intravenous application and which stabilises the nanoparticles by steric repulsion to inhibit colloidal aggregation in physiological conditions. ${ }^{18}$ The use of a heterobifunctional PEG with two different terminal moieties allows covalent attachment of an antibody to the outer end of the polyethylene glycol chain, thus maintaining availability of antibody binding sites to cell surface receptors. It has been demonstrated previously that nanoparticles modified with mixed receptor-mediated endocytosis peptide and bifunctional HS-PEG$\mathrm{COOH} 5000$ monolayers were efficiently internalised by $\mathrm{HeLa}$ cells. ${ }^{19,20}$

Despite the significant efforts to develop modified nanostructures for efficient PDT treatment, it still remains a challenge to develop a nanostructured system based on surface-functionalised gold nanoparticles that combines molecular recognition with effective production of reactive singlet oxygen under irradiation. In this study we show that it is possible to combine an efficient singlet oxygen generating hydrophobic photosensitiser with cancer-specific targeting antibodies on the surface of gold nanoparticles. Importantly, these multifunctional gold nanoparticle conjugates are water-soluble, a characteristic which is essential for antibody stability and for the facile delivery of conjugates for photodynamic treatment, but still retain the ability to generate significant levels of singlet oxygen. The preparation and properties of the 4-component (anti-HER2 antibody-phthalocyanine photosensitiser-PEG-gold nanoparticle) nanoparticle conjugates (Fig. 1) are described. Further, it is shown that the nanoparticle conjugates can be used to specifically target and then photodynamically destroy breast cancer cells which overexpress the HER2 cell surface receptor.

\section{Experimental}

\section{Materials and methods}

All solvents and reagents were reagent-grade and were used as received. Breast carcinoma cell lines (SK-BR-3 and MDA-MB-

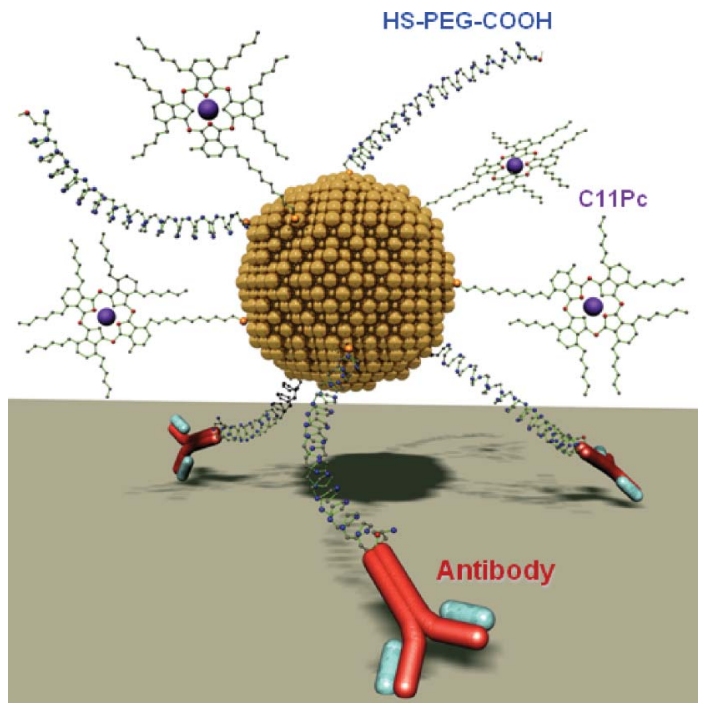

Fig. 1 The complete 4-component system of photosensitiser-nanoparticle conjugates. The conjugates incorporate the photosensitiser (a derivative of zinc(II) phthalocyanine, C11PC), the heterobifunctional HS-polyethylene glycol-COOH and the HER2 (ErbB2) mouse monoclonal antibody, all on the gold nanoparticle surface.

231) were obtained from the Cancer Research UK bank. Normal mammary epithelial cells (MCF-10A) were purchased from the American Type Cell Culture (ATCC) together with Mammary Epithelial Growth Media. Cell culture growth medium for the SKBR-3 and MDA-MB-231 cell lines was purchased from GIBCO. Cell-based assays (ApoToxGlo Triplex assay, Caspase-Glo 3/7 and CytoTox-One homogeneous membrane integrity assay) were purchased from Promega. MTT [(3-(4,5-dimethylthiazol-2-yl)2,5-diphenyltetrazolium bromide] was obtained from Sigma Aldrich. The monoclonal antibody against ErbB-2 (HER2) was purchased from Invitrogen.

UV-Visible absorption spectra were recorded on a Hitachi U3000 UV-visible spectrophotometer, while fluorescence spectra were obtained on a Hitachi F-4500 fluorescence spectrometer. All laser excitation experiments for the cell-based assays were performed using a $632.8 \mathrm{~nm} \mathrm{HeNe} \mathrm{laser} \mathrm{(Uniphase} \mathrm{1125P)} \mathrm{at} \mathrm{a} \mathrm{fluence}$ rate of $34 \mathrm{~mW} \mathrm{~cm}{ }^{-2}$ and a light dose of $10.2 \mathrm{~J} \mathrm{~cm}^{-2}$. The particle size of the antibody-photosensitiser nanoparticle conjugates was measured on a transmission electron microscope (JEOL JEM2000EX). A typical TEM image of the nanoparticle conjugates is shown in Fig. 2(A). Centrifugation of the nanoparticles was performed using a Beckman Coulter Allegra ${ }^{\mathrm{TM}}$ X-22R Centrifuge.

Elemental analysis of the photosensitiser-bound nanoparticles to determine the number of phthalocyanine molecules per nanoparticle was achieved using inductively coupled plasma-mass spectrometry (ICP-MS). The amount of gold and zinc (as a marker for the phthalocyanine photosensitiser) within the nanoparticle conjugates was measured on an Agilent 7500ce ICP-MS, fitted with a concentric Micromist nebuliser and water-cooled Scott double-pass spray chamber. The standards used for calibration were from Merck (Merck VI Multi Element Standard) for zinc and from CPL International (Single Element Gold $1000 \pm 3 \mu \mathrm{g}$ $\mathrm{ml}^{-1}$ ) for gold.

Measurements of the cell-based assays were performed on EnVision (Wallac) 2103 Multilabel Reader (Perkin Elmer) equipped 

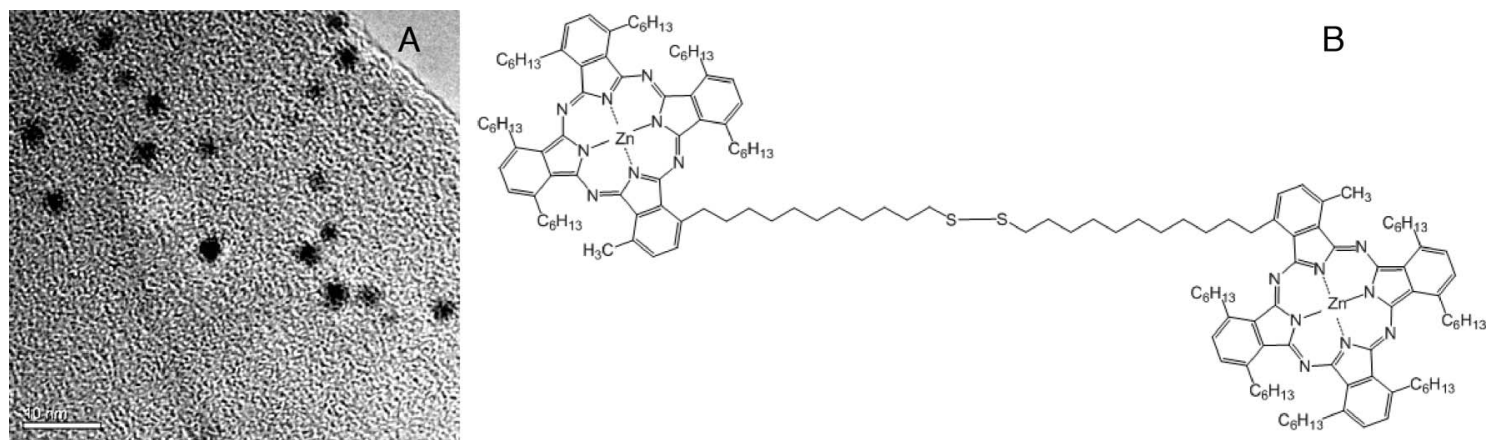

Fig. 2 (A) A TEM image of the gold nanoparticles stabilised with the $\mathrm{Zn}$ phthalocyanine photosensitiser and the HS-polyethylene glycol-COOH and with the HER2 antibody conjugated to the PEG (scale bar = $10 \mathrm{~nm})$, (B) structure of $1,1^{\prime}, 4,4^{\prime}, 8,8^{\prime}, 15,15^{\prime}, 18,18^{\prime}, 22,22^{\prime}$-tetradecakisdecyl-25,25'-(11,11'dithiodiundecyl) diphthalocyanine zinc (C11Pc). ${ }^{13-15}$

with an EnVision work station. Luminescence was measured with a $700 \mathrm{~nm}$ low-pass luminescence filter. Fluorescence was measured using excitation and emission filters recommended by the cellbased assay provider. The absorbance intensity for the colorimetric MTT assay was measured on a Dynatech MRX plate reader at $550 \mathrm{~nm}$.

The cellular uptake of the nanoparticle conjugates was observed using a confocal laser scanning microscope (Carl Zeiss, LSM 510 meta). Differential Interference Contrast (DIC) images were obtained using $633 \mathrm{~nm} \mathrm{HeNe}$ laser excitation with fluorescence emission measurement between $650-720 \mathrm{~nm}$. A $63 \times, 1.4$ NA objective was used to obtain high-resolution images.

\section{Preparation and characterisation of the 4-component nanoparticle conjugates [C11Pc-PEG-antibody-gold nanoparticles]}

The photosensitiser used in this study was $1,1^{\prime}, 4,4^{\prime}, 8,8^{\prime}, 15,15^{\prime}, 18$, $18^{\prime}, 22,22^{\prime}$-tetradecakisdecyl-25,25'-(11,11'dithiodiundecyl) diphthalocyanine zinc $(\mathrm{C} 11 \mathrm{Pc})$. The structure of this photosensitiser is shown in Fig. 2(B). This photosensitiser was prepared as previously reported. ${ }^{13-15}$ Gold nanoparticles of $c a .4 \mathrm{~nm}$ in diameter were synthesised using the method originally described by Brust et al., ${ }^{2}$ albeit with modifications. In a typical experiment, the $\mathrm{C} 11 \mathrm{Pc}$ phthalocyanine derivative $(8 \mathrm{mg})$ was dissolved in tetrahydrofuran (THF) (4 ml). PEG-COOH $3000 \mathrm{Da}(\alpha-$-thio- $\omega$ carboxy polyethylene glycol, $30 \mathrm{mg}$, Iris Biotech $\mathrm{GmbH}$ (3274 Da)) in THF $(8 \mathrm{ml})$ was added, and the mixture was stirred vigorously for $5 \mathrm{~min}$ at room temperature. Gold(III) chloride tetrahydrate $(4.8 \mathrm{mg}$ in $4.8 \mathrm{ml}$ of THF) was added to the solution with further stirring for $5 \mathrm{~min}$. An aqueous solution of sodium borohydride $(6 \mathrm{mg}$ in $4.8 \mathrm{ml}$ ) was added dropwise with continuous stirring, and the solution was further stirred at room temperature overnight in the dark. The solvent was removed by rotary evaporation at $60^{\circ} \mathrm{C}$, and the particles were re-suspended in MES (2-( $N$-morpholino)ethanesulfonic acid) buffer, $\mathrm{pH} 5.5$ with $0.05 \%$ Tween 20 (Polyoxyethylene (20) sorbitan monolaurate, a non-toxic polysorbate surfactant, obtained from Sigma-Aldrich). The particles were then centrifuged in polypropylene Eppendorf tubes $(1 \mathrm{ml})$ at $14000 \mathrm{rpm}$ for $30 \mathrm{~min}$. The supernatant containing the particles was removed from the pellet with a micropipette and then characterised using UV-visible spectrophotometry. For control experiments, PEGylated gold nanoparticles were also prepared using the same method as described above for the $\mathrm{C} 11 \mathrm{Pc}-$
PEG-gold nanoparticles, but without addition of the C11Pc phthalocyanine derivative.

Attachment of the monoclonal antibody specific to the HER2 receptors was achieved via an amide linkage to the HS-PEG-COOH 3000. The amide bond was achieved through EDC (1-ethyl-3-(3-dimethylaminopropyl) carbodiimide hydrochloride, obtained from Sigma-Aldrich) and NHS (Dhydroxysulfosuccinimide sodium salt, from Fluka) two-step coupling activation of the carboxylic group of the PEG derivative. The activation converted the carboxylic moiety of the PEG to a succinimidyl ester, which then reacts with an amine group on the antibody forming a stable amide bond between the PEG and the antibodies. ${ }^{21}$ EDC $(0.4 \mu \mathrm{l})$ and NHS $(1.1 \mathrm{mg})$ were added to $1 \mathrm{ml}$ of the photosensitiser-PEG nanoparticle conjugates, the mixture was stirred for $30 \mathrm{~min}$ at room temperature, centrifuged at $9000 \mathrm{rpm}$ for $30 \mathrm{~min}$ in ultra-filtration spin columns, and the particles were re-suspended in PBS (phosphate saline buffer $\mathrm{pH}=$ 7.4, filter sterilised). Then $1 \mu 1$ of the HER2 antibody ( $1 \mathrm{mg}$ $\mathrm{ml}^{-1}$ ) was added to $1 \mathrm{ml}$ of the activated nanoparticles, stirred for $2.5 \mathrm{~h}$, mixed by orbital shaking for $15 \mathrm{~h}$ at $1400 \mathrm{rpm}$, placed into ultrafiltration spin columns and then centrifuged at 14000 $\mathrm{rpm}$ for $30 \mathrm{~min}$. The particles were re-suspended in PBS ( $\mathrm{pH}=7.4$, filter sterilised, $400 \mu \mathrm{l}$ per column) and characterised using UVvisible spectrophotometry. The stock solution of nanoparticles in PBS was adjusted to a concentration of $5 \mu \mathrm{M}$ with respect to the C11PC phthalocyanine derivative, and diluted for the cell line tests as required.

\section{Measurement of singlet oxygen production}

The generation of intracellular reactive oxygen species by the antiHER2 antibody phthalocyanine-PEG-gold nanoparticle conjugates was determined using the molecular probe disodium, 9,10anthracenedipropionic acid (ADPA). Singlet oxygen converts the ADPA into an endoperoxide which can be monitored by UVvisible spectrophotometry. ${ }^{22} 100 \mu \mathrm{l}$ of ADPA solution (1.2 mM in methanol) was added to $900 \mu \mathrm{l}$ of the nanoparticle conjugates in a quartz cuvette and stirred thoroughly. UV-visible absorption spectra were measured in the range $300-800 \mathrm{~nm}$. The solution was irradiated using the $\mathrm{HeNe} 632.8 \mathrm{~nm}$ laser. During irradiation the solution was vigorously stirred. The production of singlet oxygen was determined by the decay of the absorbance intensity of the ADPA $400 \mathrm{~nm}$ absorption band every $5 \mathrm{~min}$ for $30 \mathrm{~min}$. 


\section{Cell culture}

Breast carcinoma cell lines (SK-BR-3 and MDA-MB-231) were routinely cultured in $75 \mathrm{~cm}^{3}$ tissue culture flasks in Dulbecco's Modified Eagle Medium (DMEM) supplemented with 10\% fetal calf serum (FCS) and 1\% L-glutamine. Normal mammary epithelial cells (MCF-10A) were cultured in $75 \mathrm{~cm}^{3}$ tissue culture flasks in ATCC complete growth medium supplemented with $100 \mathrm{ng}$ $\mathrm{ml}^{-1}$ cholera toxin. The amount of cells for each cell-based assay and cell viability was monitored by counting viable cells in a hemocytometer by using the trypan blue exclusion method. ${ }^{23}$

\section{Analysis of nanoparticle conjugate uptake by confocal microscopy}

Cells $\left(25 \times 10^{4}\right.$ cells per well $)$ were seeded onto 6 -well plates on round coverslips (diameter $18 \mathrm{~mm}$ ) in $2 \mathrm{ml}$ of DMEM growth medium and left to attach for $24 \mathrm{~h}$. The nanoparticle conjugates $(0.8 \mu \mathrm{M})$ were added and the cells were incubated for $3 \mathrm{~h}$. The cells were rinsed with $2 \mathrm{ml}$ of phosphate-buffered saline (PBS) 3 times. The DMEM medium was replaced with phenol red free medium, and the cells were mounted on a $37{ }^{\circ} \mathrm{C}$ heated stage. The cells were observed using a confocal laser scanning microscope (Carl Zeiss, LSM 510 meta) using 633 nm HeNe laser excitation with fluorescence emission measured between 650 $720 \mathrm{~nm}$. Differential Interference Contrast (DIC) images were collected simultaneously with transmitted light from the $633 \mathrm{~nm}$ excitation. In order to monitor changes in cell viability, a dead cell marker, propidium iodide, was used according to the published protocol. ${ }^{24}$ Cells were stained with propidium iodide $\left(2 \mu \mathrm{g} \mathrm{ml}^{-1}\right.$, from Invitrogen) for $10 \mathrm{~min}$ in the dark and then observed with the confocal microscope combined with DIC using $543 \mathrm{~nm} \mathrm{HeNe}$ laser excitation with fluorescence emission measured between 620 $720 \mathrm{~nm}$ (excitation/emission maximum wavelengths for propidium iodide are $536 \mathrm{~nm} / 620 \mathrm{~nm}$ respectively). Cells incubated in the absence of nanoparticle conjugates were used as a control. Images were processed and composite images were obtained using Zeiss LSM Image Browser Version 4.2.0.121.

\section{Measurement of cell viability, apoptosis and proliferation}

Cells were seeded onto 96-well plates, $1 \times 10^{4}$ cells per well in $100 \mu \mathrm{l}$ of DMEM supplemented with 10\% FCS and 1\% L-glutamine (SK-BR-3 and MDA-MB-231 cell lines) or in ATCC complete growth medium supplemented with $100 \mathrm{ng} \mathrm{ml}^{-1}$ cholera toxin (MCF-10A cell line). The cells were counted with a Neubauer hemocytometer. The 96-well plates were obtained from Fisher Thermo Scientific (Nunc) as either clear or solid white styles depending on assay requirement. Plates were incubated overnight at $37{ }^{\circ} \mathrm{C}$ under a $5 \% \mathrm{CO}_{2}$ atmosphere. The medium in the wells was then replaced with fresh medium containing the antibodyphotosensitiser nanoparticle conjugates (final concentration was $10 \mathrm{nM}$ of the phthalocyanine photosensitiser assembled on the gold nanoparticles, $c a .0 .03 \mu \mathrm{g}$ of the nanoparticle conjugates per $100 \mu \mathrm{l}$ ), and incubation continued for $2 \mathrm{~h}$ (unless specified otherwise). After incubation, the cells were washed with PBS buffer 3 times to remove non-bound nanoparticle conjugates, and the medium was replaced. Each well was then irradiated with the $\mathrm{HeNe} 632.8 \mathrm{~nm}$ laser for $5 \mathrm{~min}$ with a fluence rate of $34 \mathrm{~mW} \mathrm{~cm}^{-2}$, light dose $10.2 \mathrm{~J} \mathrm{~cm}^{-2}$. The intensity of the laser light source was measured using a power meter (Power Max 500AD Molectron).

\section{MTT assay}

The effect of the nanoparticles on cell viability was determined using the MTT (3-(4,5-dimethylthiazol-2-yl)-2,5diphenyltetrazolium bromide, Sigma) assay. ${ }^{25,26}$ Cells at a density of $1 \times 10^{4}$ cells per well were seeded on clear 96-well plates and treated with the nanoparticle conjugates as described above, followed by light irradiation with the $\mathrm{HeNe} 632.8 \mathrm{~nm}$ laser for 5 min. $10 \mu \mathrm{l}$ of the MTT solution ( $5 \mathrm{mg} \mathrm{ml}^{-1}$ in PBS) was added to each well together with $200 \mu$ l of DMEM or ATCC growth medium, depending on the cell line. The plates were further incubated for $4 \mathrm{~h}$ at $37^{\circ} \mathrm{C}$. Then the medium was removed and the resultant formazan crystals were washed with $200 \mu$ PBS (3 times) and then dissolved in $200 \mu \mathrm{l}$ of dimethyl sulfoxide. The absorbance intensity of each well was measured at $550 \mathrm{~nm}$. Each variable (concentration of nanoparticle conjugates, incubation time and irradiation time) was assessed through MTT assay in triplicate.

\section{ApoTox-Glo ${ }^{\mathrm{TM}}$ Triplex Assay}

The ApoTox-Glo ${ }^{\mathrm{TM}}$ triplex assay enables assessment of cell viability, cytotoxicity and caspase activation events within a single assay well. The first part of the assay simultaneously measures two protease activities: one is a marker of cell viability (glycylphenylalanyl-aminofluorocoumarin; GF-AFC), and the other is a marker of cytotoxicity (bis-alanylalanyl-phenylalanylrhodamine 110; bis-AAF-R110). The live- and dead-cell proteases produce different products, AFC and R110 respectively, which have different excitation and emission spectra, allowing them to be detected simultaneously. The protocol is combined with the luminescent Caspase-Glo 3/7 assay to monitor cell apoptosis. The apoptotic response was reflected by an increase in caspase-3/7 activity, whereas the cytotoxic responses were marked by decreases in AFC (live cell) fluorescence and increases in R110 (dead cell) fluorescence. ${ }^{27}$

Cells at a density of $1 \times 10^{4}$ cells per well were seeded on solid white 96-well plates and treated with nanoparticle conjugates followed by irradiation as described above. $20 \mu \mathrm{l}$ of viability/cytotoxicity reagent containing both GF-AFC substrate and bis-AAF-R110 substrate was added to all wells, and the content was mixed by orbital shaking for one minute. The cells were incubated for $1 \mathrm{~h}$ at $37{ }^{\circ} \mathrm{C}$, and the two fluorescence signals were recorded simultaneously. The fluorescence signal to determine cell viability was recorded with $400_{\mathrm{Ex}} / 505_{\mathrm{Em}}$ filters, and the fluorescence signal monitoring the cell cytotoxicity was recorded using $485_{\mathrm{Ex}} / 520_{\mathrm{Em}}$ filters. After measurement of cell viability and cytotoxicity, $100 \mu \mathrm{l}$ of the Caspase-Glo 3/7 assay was added to all wells, and the luminescence signal from the caspase$3 / 7$ activation was measured after $30 \mathrm{~min}$ of incubation. Each plate had the cells without any treatment as negative controls. Staurosporine $(10 \mu \mathrm{M}, 1 \mu \mathrm{l}$ per $100 \mu \mathrm{l}$ from $1 \mathrm{mM}$ stock in DMSO) was used as an apoptosis positive control. Lysis solution Triton X $100(2 \mu 1$ per $100 \mu 1$ from 9\% stock in DMSO) was used as a positive control to induce the cell death. Each experiment was performed in triplicate.

\section{CytoTox-ONE ${ }^{\mathrm{TM}}$ homogeneous membrane integrity assay}

The CytoTox-ONE ${ }^{\mathrm{TM}}$ Assay is a rapid, fluorescent measure of the release of lactate dehydrogenase $(\mathrm{LDH})$ from cells with a 
damaged membrane. LDH released into the culture medium is measured with a 10-minute coupled enzymatic assay that results in the conversion of resazurin to resorufin. The reaction can be performed directly in a homogeneous format in assay wells containing a mixed population of viable and damaged cells. ${ }^{28}$ Cells $\left(1 \times 10^{4}\right.$ cells ml $\left.^{-1}\right)$ were placed in 96-well white plates in $100 \mu 1$ of DMEM or ATCC growth medium, depending on the cell line and incubated with the nanoparticle conjugates as described above. The plates were equilibrated at room temperature for $30 \mathrm{~min}$. $100 \mu 1$ of CytoTox-ONE ${ }^{\mathrm{TM}}$ reagent was added to each well and the plates were incubated for $10 \mathrm{~min}$ at room temperature. The fluorescence signal monitoring the cell proliferation was recorded with $560_{\mathrm{Ex}} / 590_{\mathrm{Em}}$ filters. Lysis solution (Triton X $1009 \%$ ) was used as a positive control for maximum LDH release. Cytotoxicity was expressed relative to the basal LDH release from untreated control cells.

\section{Results and discussion}

In order to develop multifunctional gold nanoparticles as a potential drug delivery system for PDT, a 4-component system consisting of a phthalocyanine derivative as the photosensitiser together with a heterobifunctional polyethylene glycol (HS-PEG$\mathrm{COOH}$ ) was self-assembled onto the gold nanoparticle surface. These functionalised gold nanoparticles were then conjugated with HER 2 monoclonal antibodies. The HER2 antibodies specifically bind to HER2 receptors which are over-expressed on the cellular surface in $c a .25 \%$ of all breast cancer cases. ${ }^{29}$

The C11Pc phthalocyanine derivative used in this work has been shown previously to be a hydrophobic and an efficient sensitiser of singlet oxygen $\left(\Phi_{\Delta}=0.45\right) \cdot{ }^{14}$ To deliver this photosensitiser for PDT, previously we synthesised gold nanoparticles using the Brust method ${ }^{2}$ which incorporated a phase transfer reagent, tetraoctylammonium bromide, together with the phthalocyanine as a stabilising self-assembled monolayer. ${ }^{14}$ These phthalocyanine nanoparticles were soluble in polar solvents, such as ethanol, and were shown to be useful PDT agents for the destruction of HeLa cervical cancer cells. ${ }^{13}$ In order to develop watersoluble photosensitiser-gold nanoparticles, we have modified the synthetic strategy to incorporate a polyethylene glycol (HSPEG-COOH, $3 \mathrm{kDa}$ ). This bifunctional PEG contains a thiol group for self-assembly onto the gold surface and a terminal carboxy group for coupling of antibodies. Solutions of the $\mathrm{C} 11 \mathrm{Pc}$ phthalocyanine derivative and the HS-PEG-COOH were combined. Gold nanoparticles were synthesised in this solution in order to form a mixed self-assembled monolayer surrounding the particles. The co-assembled species stabilised the $c a .4 \mathrm{~nm}$ gold nanoparticles. The phthalocyanine-PEG-gold nanoparticles were found to be soluble and stable in aqueous solutions. For future in vivo studies, an additional advantage of coating gold nanoparticles with polyethylene glycol is that it has been shown to increase the blood circulation time of the nanoparticles and subsequent accumulation within tumours. ${ }^{4}$

To achieve a targeting capability towards breast cancer cells that overexpress the HER2 cell surface receptor, the phthalocyaninePEG-gold nanoparticles were conjugated with anti-HER2 antibodies. A surfactant, Tween $20(0.05 \%$ in buffer $)$, was initially added to the phthalocyanine-PEG-gold nanoparticles. This detergent was used to aid the dispersion of the nanoparticles in water and physiological solutions, ${ }^{30}$ and is commonly used as a washing agent in immunoassays (such as Western blots or ELISAs) to prevent non-specific antibody binding. ${ }^{31}$ Additionally, it has also been shown that a small amount of surfactant can be used to prevent zinc(II) phthalocyanine agglomeration in order to secure high singlet oxygen production. ${ }^{32}$ Following the EDC/NHS two-step antibody coupling chemistry, the resultant anti-HER 2 antibodyphthalocyanine-PEG-gold nanoparticle conjugates were washed and re-suspended in phosphate-buffered saline without any surfactant in order to decrease the risk of cell lysis and membrane protein solubilisation during cell treatment. A TEM image of the stabilised 4-component nanoparticle conjugates is shown in Fig. 2(A).

To ensure that high levels of singlet oxygen are produced, it is important to avoid excessive dimerisation of the phthalocyanine photosensitiser, since a higher degree of aggregation leads to a loss of central metal accessibility and, as a result, to a significant decrease of photocatalytic activity. ${ }^{33}$ The presence of a monomer-dimer equilibrium of the phthalocyanine derivative in solutions was observed previously via UV-visible absorption spectrum as specific electronic transitions in the Q band $(\lambda=$ $600-800 \mathrm{~nm}$ ). ${ }^{14,33,34}$ We have tested the degree of phthalocyanine derivative agglomeration on the surface of gold nanoparticles using UV-visible absorption spectrometry at various stages of the nanoparticle conjugate preparation. Fig. 3 shows a visible absorption spectrum of the zinc(II) phthalocyanine derivative as part of the 4-component nanoconjugates. Two strong absorption bands in the far-red region of the visible spectrum correspond to monomeric $\left(\lambda_{\max }\right.$ (monomer) ca. $\left.698 \mathrm{~nm}\right)$ and dimeric $\left(\lambda_{\max }(\right.$ dimer $)$ $c a .644 \mathrm{~nm}$ ) forms of the octyl-substituted zinc(II) phthalocyanine derivative, respectively..$^{14,34}$ Comparison of the spectrum of the same conjugates but prior to antibody attachment (Fig. 3, inset)

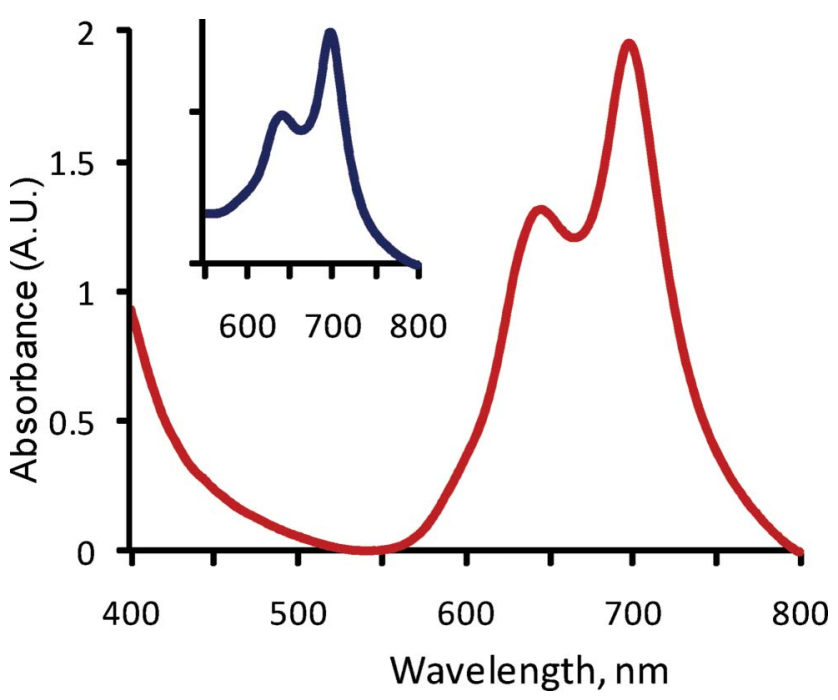

Fig. 3 Visible absorption spectrum of the $\mathrm{Zn}$-phthalocyanine photosensitiser together with HS-polyethylene glycol-COOH supported on gold nanoparticles and conjugated with anti-HER2 antibody; absorption at $698 \mathrm{~nm}$ and $644 \mathrm{~nm}$ corresponds to monomeric and dimeric form of the phthalocyanine photosensitiser respectively. Inset: Visible absorption spectrum of the $\mathrm{Zn}$-phthalocyanine photosensitiser together with the HS-polyethylene glycol-COOH on the gold nanoparticles without antibody attached. The ratio between monomeric and dimeric form of the phthalocyanine was not affected by antibody attachment, thus preserving the high rate of reactive singlet oxygen production. 
confirmed that the photosensitiser was successfully attached to the surface of gold nanoparticles, and that the ratio between monomeric and dimeric form of the $\mathrm{C} 11 \mathrm{Pc}$ derivative was not affected by antibody attachment. ICP-MS analysis of the gold nanoparticle conjugates suggests that approximately 10 molecules of the $\mathrm{C} 11 \mathrm{Pc}$ phthalocyanine derivative are attached to each nanoparticle (assuming that the ligand stabilised gold clusters are cuboctahedrons and that each nanoparticle consists of 309 gold atoms $\mathrm{s}^{2,35,36}$ ).

For use in photodynamic therapy, the nanoparticle conjugates must be capable of producing significant levels of cytotoxic singlet oxygen. The production of singlet oxygen is readily monitored using the molecular probe disodium 9,10-anthracenedipropionic acid (ADPA). ${ }^{22}$ In this present study, ADPA was used as the molecular probe to confirm the photoactivity of the 4-component nanoparticle conjugates. Under red light $(633 \mathrm{~nm})$ irradiation, the 4-component nanoparticle conjugates generated singlet oxygen, which converted the ADPA into an endoperoxide. This chemical change in ADPA can be monitored directly by UV-visible spectrophotometry via the characteristic absorption band at $400 \mathrm{~nm}$. Fig. 4 shows the time-dependent decay of the absorption spectrum of ADPA following irradiation of the nanoparticle conjugates. A large decrease in the intensity of the ADPA absorption band occurs within the first $5 \mathrm{~min}$ of irradiation (Fig. 4(A)), indicating the conversion of the ADPA to the endoperoxide and the presence of a high amount of singlet oxygen. After $30 \mathrm{~min}$ of irradiation, nearly $80 \%$ of the ADPA has been converted to the endoperoxide. To ensure that the decreasing absorbance intensity of the ADPA was not due to changes of the absorption spectrum of the C11Pc phthalocyanine photosensitiser, the nanoparticle conjugates were irradiated without the singlet oxygen probe. Fig. 4(B) shows that the Soret band of the phthalocyanine on the nanoparticle conjugates exhibits a slight decrease in intensity over the $30 \mathrm{~min}$ irradiation period. The decrease of intensity of the Soret and the absorption bands at 698 and $645 \mathrm{~nm}$ is possibly due to partial photodecomposition of the phthalocyanine on formation of the singlet oxygen. ${ }^{34}$ However, it is apparent that the decreasing absorption spectrum of the ADPA, seen in Fig. 4(A), is significantly larger and is due to the production of singlet oxygen by the nanoparticle conjugates. To determine whether the singlet oxygen produced by the nanoparticle conjugates is due to the presence of the photosensitiser, control particles were prepared without the $\mathrm{C} 11 \mathrm{Pc}$ phthalocyanine derivative - the rates of the decay of the $400 \mathrm{~nm}$ absorption band were then compared (Fig. $4(C)$ ). Monitoring the absorbance at a wavelength of $400 \mathrm{~nm}$ for the nanoparticle conjugates with and without the C11Pc shows that the photosensitiser is essential for the production of singlet oxygen.

A comparison of phthalocyanine-PEG nanoparticles with and without antibody attached was also made. It was determined that attachment of the anti-HER2 antibody did not affect the rate of singlet oxygen production. This result is consistent with the measurements of the amount of photocatalytically active monomeric form of the $\mathrm{Zn}$ (II) phthalocyanine present on the nanoparticle surface, which remains unchanged when compared to the spectrum of the nanoparticle conjugates prior to the covalent attachment of the HER2 antibodies (Fig. 3). The presence of the polyethylene glycol on the gold nanoparticle surface possibly stabilises an active monomeric form of photosensitiser through
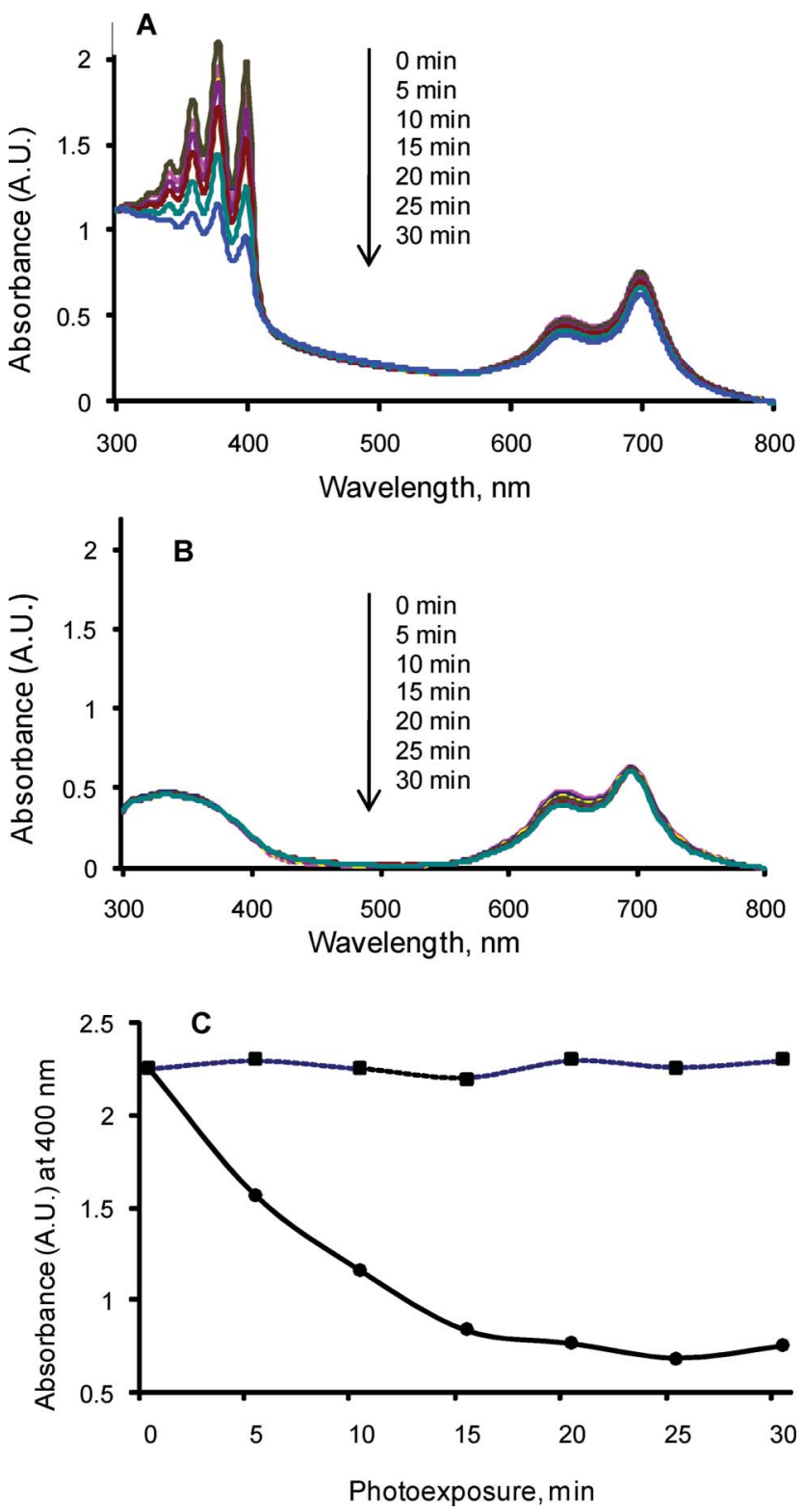

Fig. 4 (A) Time-dependent decay of ADPA absorption spectrum as a result of photobleaching after irradiation in the presence of the 4-component gold nanoparticle conjugates. (B) Time-dependent decay of the C11Pc-PEG-gold nanoparticle absorption spectrum after irradiation (C) Singlet oxygen production as monitored by the photobleaching of ADPA absorption band at $400 \mathrm{~nm}$ after irradiation (HeNe laser, $633 \mathrm{~nm}$ ) of the 4-component nanoparticle conjugates antibody-C11Pc-PEG-gold nanoparticles (dots) and antibody-PEG-nanoparticles (with no C11Pc) (squares, control).

steric repulsion, thus preserving an efficient rate of singlet oxygen production even without addition of a surfactant.

To determine the suitability of the 4-component nanoparticle conjugates for PDT, in vitro studies using a breast cancer cell line that overexpress the HER2 epidermal growth factor receptors on the cellular surface (SK-BR-3) and a breast cancer cell line without the receptor overexpression (MDA-MB-231) were performed. Since the phthalocyanine derivative on the nanoparticle conjugates is fluorescent, ${ }^{13}$ it is possible to visualise the cellular uptake and distribution of the nanoparticle conjugates within the 

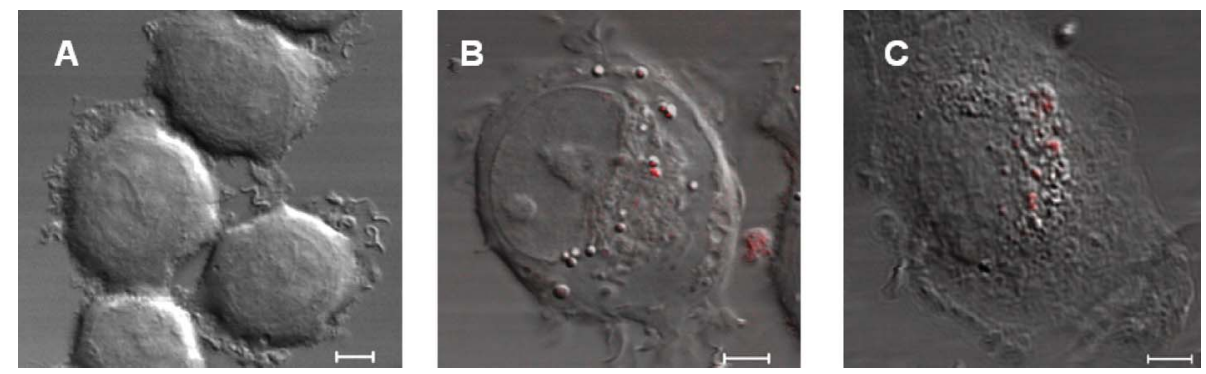

Fig. 5 Combined confocal fluorescence and DIC images of non-treated cells (A, SK-BR-3 cell line) and cells after incubation with the 4-component gold nanoparticle conjugates, [C11Pc] $=0.4 \mu \mathrm{M}$ : (B, SK-BR-3 cell line) and (C, MDA-MB-231 cell line). The presence of the nanoparticle conjugates within the cells can be readily seen from the red fluorescence emission following laser excitation at $633 \mathrm{~nm}$. Scale bars are $5 \mu \mathrm{m}$ in all images.

cancer cells using confocal fluorescence microscopy. Considering the small size and near-spherical shape of the nanoparticles (properties that have reported to be favourable for cellular uptake $\mathrm{e}^{37}$ ), it was envisaged that the cells would internalise the nanoparticle conjugates through endocytotic processes from the extracellular environment. Confocal microscopy images (Fig. 5) show that when the nanoparticle conjugates were incubated with the cancer cells for $3 \mathrm{~h}$, they are taken up, thus delivering the phthalocyanine photosensitiser directly into the cell interior. In comparison to untreated cells (Fig. 5(A)), the nanoparticle conjugates can be readily seen from the red fluorescence emission following laser excitation at $633 \mathrm{~nm}$ for the SK-BR-3 and MDA-MB-231 cell lines (Fig. 5(B) and (C) respectively). The images demonstrate a high level of cellular uptake of the nanoparticle conjugates by the breast cancer cell lines; following irradiation with the red light, morphological changes to the cellular structure were indicative of cell mortality.

Further evidence of increased cell mortality following photodynamic treatment with the nanoparticle conjugates was provided through a series of cell-based assays in vitro. The colorimetric MTT metabolic activity assay adapted to incorporate a cell irradiation protocol $^{25,26}$ was used to determine cell viability. The SK-BR3 cell line (cells with HER2 receptors) was used as a target cell line and contrasted with the MDA-MB-231 breast cancer cell line that does not over-express HER2 and with normal (healthy) mammary epithelial cells MCF-10A. The 4-component nanoparticle conjugates were added to each of the three cell lines and incubated for $2 \mathrm{~h}$. The amount of nanoparticle conjugates was about $0.4 \mathrm{ng}$ in $1 \mu \mathrm{l}$ of phosphate-buffered saline, equivalent to $10 \mathrm{nM}$ of the monomeric form of C11Pc in each well. After incubation, cells were washed thoroughly with buffer to remove the nanoparticle conjugates that had not been internalised, and then each well was irradiated with a red light $(633 \mathrm{~nm} \mathrm{HeNe}$ laser, total irradiation dose $10.2 \mathrm{~J} \mathrm{~cm}^{-2}$ ). The cells were incubated for a further $18 \mathrm{~h}$ before proceeding with the MTT assay. Fig. 6 (A) shows the results of the MTT assay; the cell viability decreases after treatment with the nanoparticle conjugates and laser irradiation. The loss of the cell viability is significantly higher for the SK-BR-3 cell line than that for the cells without HER2 receptor amplification. For the SK-BR-3 cell line, the cell viability decreased by $60 \%$ after treatment with the 4-component nanoparticle conjugates as compared to non-treated control cells. The breast cancer MDAMB-231 cell line exhibited a $25 \%$ loss of viability while the normal mammary epithelial cells MCF-10A only showed a 7\% loss of viability. Cells without nanoparticle conjugate treatment, or treated with nanoparticles that did not have the photosensitiser attached, displayed only a limited decrease in viability following the same treatment regime. An assessment of the damage to the cellular membrane following photodynamic treatment with the 4-component nanoparticle conjugates for all three cell lines was performed using the CytoTox-One ${ }^{\mathrm{TM}}$ homogeneous membrane integrity assay. This assay is a fluorescent measure of the release of lactate dehydrogenase (LDH) from cells with a damaged membrane. ${ }^{28}$ Similar to the cell viability results using the MTT metabolic activity assay, membrane permeability was not compromised in normal mammary epithelial cells MCF-10A. However, the highest level of membrane damage was observed for the SK-BR-3 cell line with HER2 amplification following PDT treatment with the 4-component nanoparticle conjugates. These results strongly suggest that the anti-HER2 antibody-conjugated nanoparticles bind specifically to the cells that overexpress the HER2 receptor, thereby enabling targeted destruction of these breast cancer cells.

In a further assessment of cellular damage, propidium iodide (PI) was used as a molecular probe for the direct observation with confocal fluorescent microscopy of cell damage following PDT treatment. Propidium iodide intercalates with double-stranded nucleic acids; it is excluded by viable cells but can penetrate cell membranes of dying or dead cells. ${ }^{24}$ It was observed that after treatment with the 4-component nanoparticle conjugates and exposure to red laser light at $633 \mathrm{~nm}$ for $10-15 \mathrm{~min}$ the SK-BR3 breast cancer cells dramatically change morphology, with the membrane damage as shown for the PI stained cells (Fig. 6(B)). Further detailed investigation of the cells showed that chromatin fragments had formed within the SK-BR-3 cells (Fig. 6(B) insert). Such fragments are indicative of significant membrane damage, as shown by propidium iodide penetration and binding to nucleic acids inside the cell.

Finally, a further assay, the ApoTox-Glo ${ }^{\mathrm{TM}}$ Triplex Assay was used to assess cell viability, cytotoxicity and caspase activation events within a single assay well. ${ }^{27}$ Fig. 7 shows the differing response to PDT treatment for the cell lines with and without HER2 amplification. The first part of the assay simultaneously measures two protease activities, one is a marker of cell viability, and the other is a marker of cytotoxicity. The live- and dead-cell proteases produce different products; one is a marker of cell viability (glycylphenylalanyl-aminofluorocoumarin; GF-AFC), and the other is a marker of cytotoxicity (bis-alanylalanyl-phenylalanylrhodamine 110; bis-AAF-R110). AFC and R110 have different excitation and emission spectra, allowing them to be detected 

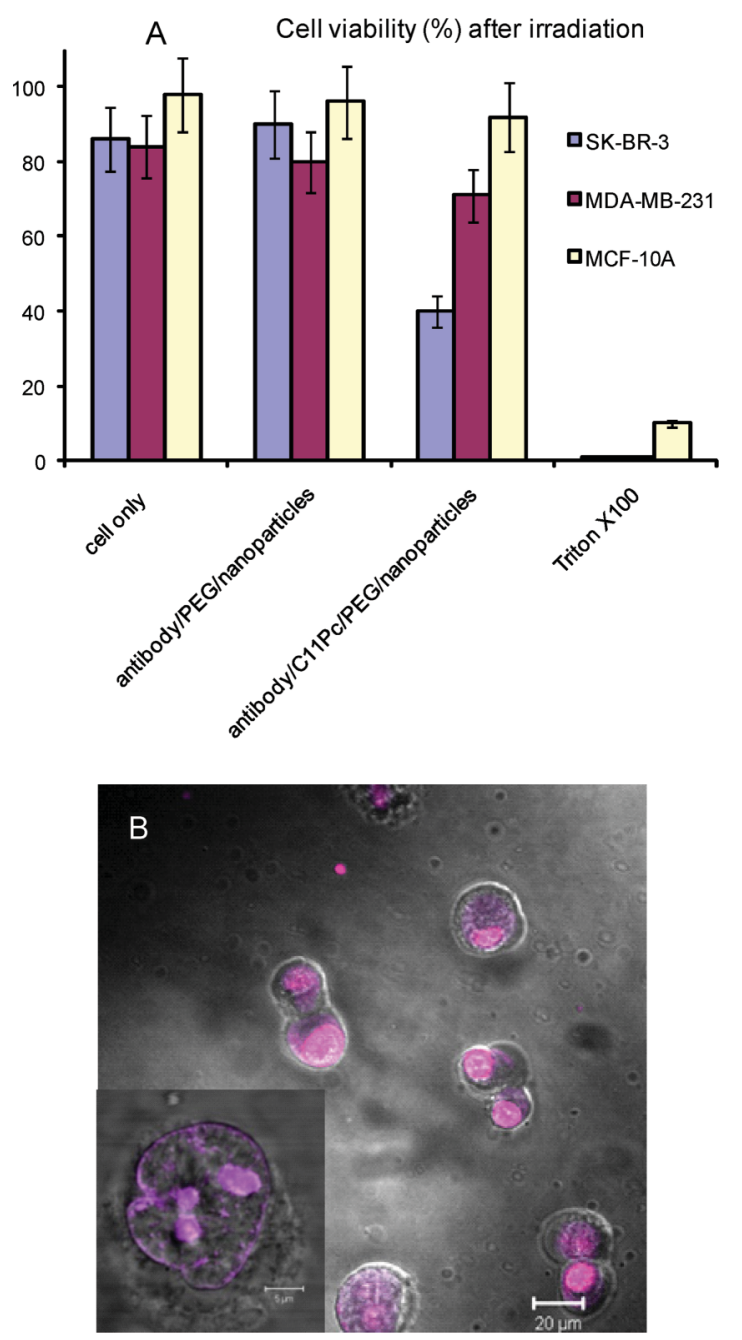

Fig. 6 (A) Viability (MTT assay) of the three different cell lines SK-BR-3, MDA-MB-231 and MCF-10A, represented as percentage of viable cells after $3 \mathrm{~h}$ treatment with nanoparticle conjugates $(10 \mathrm{nM})$ and illumination at $633 \mathrm{~nm}\left(\mathrm{HeNe}\right.$ laser, dose $\left.10.2 \mathrm{~J} \mathrm{~cm}^{-2}\right)$. Viability of the breast cancer cell line SK-BR-3 with HER2 amplification significantly decreased after treatment with the 4-component nanoparticle conjugates and irradiation as compared to the breast cancer cells without HER2 amplification (MDA-MB-231) and normal mammary epithelial cells (MCF-10A). Each experiment was performed in triplicate, and each experiment was performed on 3 separate occasions. Error bars represent the relative standard error. (B) Confocal microscopy/DIC image of SK-BR-3 cell line after treatment with the nanoparticle conjugates and illumination following propidium iodide staining. Inset: Propidium iodide penetrates cell membranes of dying or dead cells and intercalates into double-stranded nucleic acids; formation of chromatin fragments was observed.

simultaneously. ${ }^{27}$ The results demonstrated that the level of cytoxicity rises significantly for SK-BR-3 on the first day following PDT treatment with the 4-component nanoparticle conjugates, with a complementary decrease in cell viability compared to controls (non-treated cells) (Fig. 7 (A) and (B) respectively). However for the MDA-MB-231 cells (breast cancer cell line without HER2 amplification), only a moderate rise of cytotoxicity was observed when the cells were treated under the same conditions (Fig. 7(A) and Fig. 7(B)).
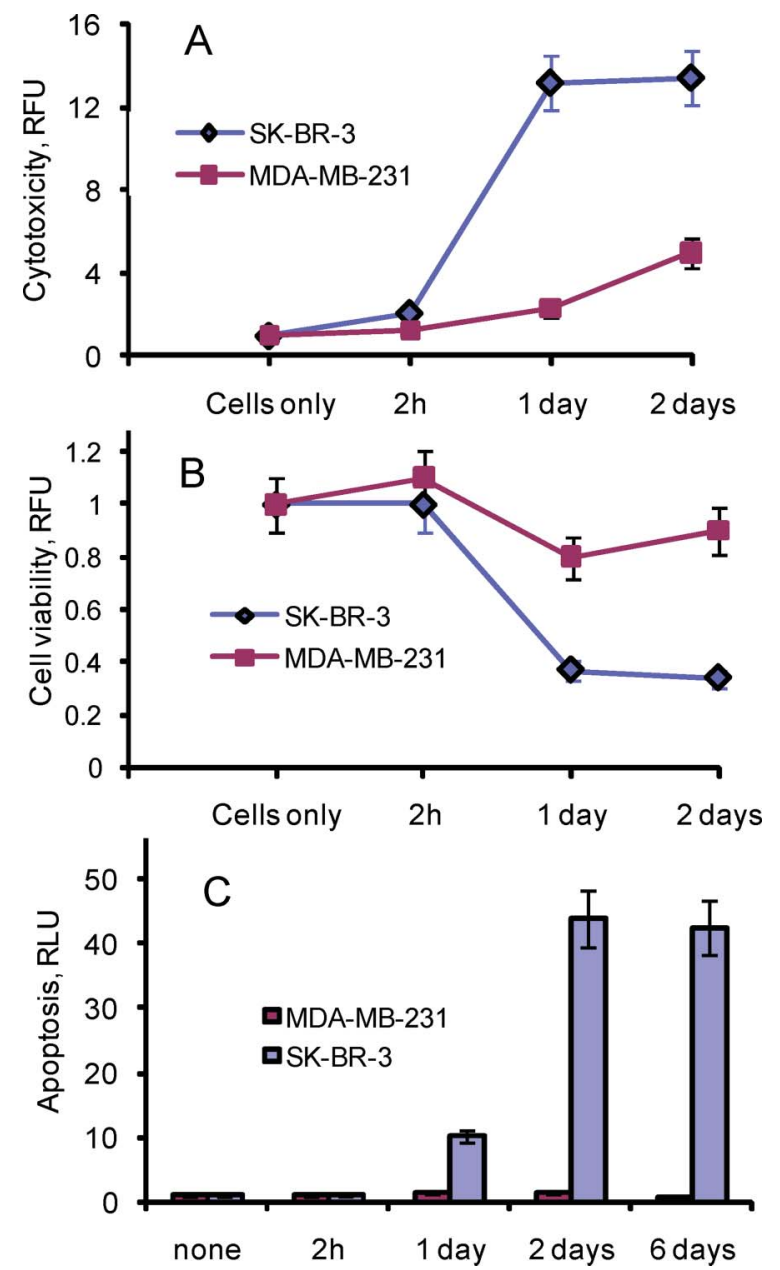

Fig. 7 Response to PDT treatment for the breast cancer cell lines with (SK-BR-3) and without (MDA-MB-231) HER2 amplification: (A) increase in cytotoxicity, (B) decrease in cell viability, (C) increase in apoptosis as a function of time after treatment of the SK-BR-3 and MDA-MB-231 cell lines with the 4-component nanoparticle conjugates $(10 \mathrm{nM})$ and illumination at $633 \mathrm{~nm}\left(\mathrm{HeNe}\right.$ laser, $\left.10.2 \mathrm{~J} \mathrm{~cm}^{-2}\right)$. Data from the ApoTox-Glo ${ }^{\mathrm{TM}}$ Triplex Assay, represented in relative fluorescent units (RFU) or relative luminescent units (RLU) normalised to the fluorescence or luminescence signal of non-treated cells with background signal from growth media subtracted. Each experiment was performed in triplicate, and each experiment was performed on 3 separate occasions. Error bars represent the relative standard error.

Measurement of cell viability and cytotoxicity in the triplex assay is combined with the bioluminescent detection of caspase$3 / 7$ to monitor cell apoptosis. The apoptotic response was reflected by an increase in caspase-3/7 activity at different incubation times after the cell lines were treated with the nanoparticle conjugates followed by irradiation (Fig. 7(C)). The apoptotic response increased sharply for the SK-BR-3 cell line on the first and second day after PDT treatment, as indicated by the increasing luminescence signal of the assay. In contrast, for the MDA-MB-231 cell line without HER2 amplification, only a low level of apoptosis was detected following the same time periods and conditions of red light illumination.

It is known that the singlet oxygen species lifetime is limited (less than $3.5 \mu \mathrm{s}$ ) and that this cytotoxic species can diffuse only 0.01 to $0.02 \mu \mathrm{m}$, which means that the photodamage is limited 
to the site of concentration of the photosensitiser ${ }^{38}$ Depending on the drug localisation within the cell, the cell death mechanism may be different. Generally, localisation of the photosensitiser to the mitochondria or the endoplasmic reticulum causes apoptosis; however, if the apoptotic route is blocked, the damaged cell will still die using the autophagic or necrotic pathways. ${ }^{39,40}$ Primary photo-damage sites for cells treated with $\mathrm{Zn}$ (II) phthalocyanine have been shown to be the Golgi apparatus with cell necrosis as the prevailing mode of cell death; mitochondrial localisation of $\mathrm{Zn}$ (II) phthalocyanine was detected only after prolonged incubation of cells with the drug, promoting cell death via an apoptotic pathway. ${ }^{41}$ In our study we observed a significant increase in apoptosis for the SK-BR-3 cell line after treatment with the 4component nanoparticles conjugated with the HER2 antibody (Fig. 7 (C)). The high level of apoptosis suggests a much higher affinity of the nanoparticle conjugates towards the SK-BR-3 cell line due to the overexpressed HER2. Fast delivery of the photosensitiser to the intracellular environment possibly promotes mitochondrial localisation, so that the cells die largely via the apoptotic pathway. Further study of the sub-cellular localisation of the 4-component gold nanoparticle conjugates is required to establish a correlation between the mechanism of cell death and the primary sites of photo-damage.

\section{Conclusions}

In summary, we have developed a 4-component nanoparticle conjugate which is capable of specifically targeting and then photodynamically treating cancer cells. To achieve the specificity, we have combined both a phthalocyanine photosensitiser drug and a primary antibody, specific to cell surface receptors, on a gold nanoparticle. Attachment of the anti-HER2 antibodies to the gold nanoparticle conjugates leads to enhanced drug targeting of breast cancer cells that overexpress the HER2 receptor on the cellular surface. Results from several in vitro cell-based assays suggests that the targeting capability of the 4-component nanoparticle conjugates enhances the efficacy of PDT cell death when tumourassociated antigens are present on the cytoplasmic membrane of the malignant cells. These first results of the treatment of breast cancer cells are very promising, and demonstrate that the 4-component nanoparticle conjugates have a great potential for targeted photodynamic therapy.

\section{Acknowledgements}

Financial support from the Big C Cancer Charity (Grant Number 08-05R) is gratefully acknowledged. The assistance of Dr Paul Thomas and Robert Posey with the confocal fluorescence microscopy and the ICP-MS analysis respectively is also gratefully acknowledged.

\section{References}

1 P. Chen, S. Mwakwari and A. Oyelere, Gold nanoparticles: From nanomedicine to nanosensing, Nanotechnology, 2008, 1, 45-66.

2 M. Brust, M. Walker, D. Bethell, D. J. Schiffrin and R. Whyman, Synthesis of thiol-derivatised gold nanoparticles in a two-phase liquidliquid system, J. Chem. Soc., Chem. Commun., 1994, 801-802.

3 C. J. Ackerson, P. D. Jadzinsky and R. D. Kornberg, Thiolate ligands for synthesis of water-soluble gold clusters, J. Am. Chem. Soc., 2005, 127, 6550-6551.
4 D. K. Chatterjee, L. S. Fong and Y. Zhang, Nanoparticles in photodynamic therapy: An emerging paradigm, Adv. Drug Delivery Rev., 2008, 60, 1627-1637.

5 J. Chen, D. Wang, J. Xi, L. Au, A. Siekkinen, A. Warsen, Z. Y. Li, H. Zhang, Y. Xia and X. Li, Immuno gold nanocages with tailored optical properties for targeted photothermal destruction of cancer cells, Nano Lett., 2007, 7, 1318-1322.

6 X. Huang, I. H. El-Sayed, W. Qian and M. A. El-Sayed, Cancer cell imaging and photothermal therapy in the near-infrared region by using gold nanorods, J. Am. Chem. Soc., 2006, 128, 2115-2120.

7 L. R. Hirsch, R. J. Stafford, J. A. Bankson, S. R. Sershen, B. Rivera, R. E. Price, J. D. Hazle, N. J. Halas and J. L. West, Nanoshell-mediated near-infrared thermal therapy of tumors under magnetic resonance guidance, Proc. Natl. Acad. Sci. U. S. A., 2003, 100, 13549-13554.

8 P. Mukherjee, R. Bhattacharya, N. Bone, Y. K. Lee, C. R. Patra, S. Wang, L. Lu, C. Secreto, P. C. Banerjee, M. J. Yaszemski, N. E. Kay and D. Mukhopadhyay, Potential therapeutic application of gold nanoparticles in $\beta$-chronic lymphocytic leukemia (BCLL): enhancing apoptosis, J. Nanobiotechnol., 2007, 5, 4.

9 X. Huang, W. Qian, I. H. El-Sayed and M. A. El-Sayed, The potential use of the enhanced nonlinear properties of gold nanospheres in photothermal cancer therapy, Lasers Surg. Med., 2007, 39, 747753.

10 R. R. Allison, H. C. Mota, V. S. Bagnato and C. H. Sibata, Bionanotechnology and photodynamic therapy - State of the art review, Photodiagn. Photodyn. Ther., 2008, 5, 19-28.

11 C. M. Allen, W. M. Sharman and J. E. Van Lier, Current status of phthalocyanines in the photodynamic therapy of cancer, J. Porphyrins Phthalocyanines, 2001, 5, 161-169.

12 S. B. Brown, E. A. Brown and I. Walker, The present and future role of photodynamic therapy in cancer treatment, Lancet Oncol., 2004, 5, 497-508.

13 M. E. Wieder, D. C. Hone, M. J. Cook, M. M. Handsley, J. Gavrilovic and D. A. Russell, Intracellular photodynamic therapy with photosensitizer-nanoparticle conjugates: cancer therapy using a 'Trojan horse', Photochem. Photobiol. Sci., 2006, 5, 727-734.

14 D. C. Hone, P. I. Walker, R. Evans-Gowing, S. FitzGerald, A. Beeby, I. Chambrier, M. J. Cook and D. A. Russell, Generation of cytotoxic singlet oxygen via phthalocyanine-stabilized gold nanoparticles: A potential delivery vehicle for photodynamic therapy, Langmuir, 2002, 18, 2985-2987.

15 M. Camerin, M. Magaraggia, M. Soncin, G. Jori, M. Moreno, I. Chambrier, M. J. Cook and D. A. Russell, The in vivo efficacy of phthalocyanine-nanoparticle conjugates for the photodynamic therapy of amelanotic melanoma, Eur. J. Cancer, 2010, 46, 1910-1918.

16 M. Zhang, T. Murakami, K. Ajima, K. Tsuchida, A. S. D. Sandanayaka, O. Ito, S. Iijima and M. Yudasaka, Fabrication of $\mathrm{ZnPc} /$ protein nanohorns for double photodynamic and hyperthermic cancer phototherapy, Proc. Natl. Acad. Sci. U. S. A., 2008, 105, 14773 14778 .

17 W. Eck, G. Craig, A. Sigdel, G. Ritter, L. J. Old, L. Tang, M. F. Brennan, P. J. Allen and M. D. Mason, PEGylated gold nanoparticles conjugated to monoclonal F19 antibodies as targeted labeling agents for human pancreatic carcinoma tissue, ACS Nano, 2008, 2, 2263-2272.

18 Y. Cheng, A. C. Samia, J. D. Meyers, I. Panagopoulos, B. Fei and C. Burda, Highly efficient drug delivery with gold nanoparticle vectors for in vivo photodynamic therapy of cancer, J. Am. Chem. Soc., 2008, 130, 10643-10647.

19 S. Herrwerth, T. Rosendahl, C. Feng, J. Fick, W. Eck, M. Himmelhaus, R. Dahint and M. Grunze, Covalent coupling of antibodies to selfassembled monolayers of carboxy-functionalized poly(ethylene glycol): Protein resistance and specific binding of biomolecules, Langmuir, 2003, 19, 1880-1887.

20 Y. Liu, M. K. Shipton, J. Ryan, E. D. Kaufman, S. Franzen and D. L. Feldheim, Synthesis, stability, and cellular internalization of gold nanoparticles containing mixed peptide-poly(ethylene glycol) monolayers, Anal. Chem., 2007, 79, 2221-2229.

21 Z. Grabarek and J. Gergely, Zero-length crosslinking procedure with the use of active esters, Anal. Biochem., 1990, 185, 131-135.

22 B. A. Lindig, M. A. J. Rodgers and A. P. Schaap, Determination of the lifetime of singlet oxygen in $\mathrm{D}_{2} \mathrm{O}$ using 9,10 -anthracenedipropionic acid, a water-soluble probe, J. Am. Chem. Soc., 1980, 102, 55905593.

23 S. Tolnai, A method for viable cell count, Tissue Culture Association Manual, 1975, 1, 37-38. 
24 D. T. Sasaki, S. E. Dumas and E. G. Engleman, Discrimination of viable and non-viable cells using propidium iodide in two color immunofluorescence, Cytometry, 1987, 8, 413-420.

25 T. Mosmann, Rapid colorimetric assay for cellular growth and survival: application to proliferation and cytotoxicity assays, J. Immunol. Methods, 1983, 65, 55-63.

26 I. Roy, T. Y. Ohulchanskyy, H. E. Pudavar, E. J. Bergey, A. R. Oseroff, J. Morgan, T. J. Dougherty and P. N. Prasad, Ceramic-based nanoparticles entrapping water-insoluble photosensitizing anticancer drugs: A novel drug-carrier system for photodynamic therapy, J. Am. Chem. Soc., 2003, 125, 7860-7865.

27 A. L. Niles, R. A. Moravec, P. E. Hesselberth, M. A. Scurria, W. J. Daily and T. L. Riss, A homogeneous assay to measure live and dead cells in the same sample by detecting different protease markers, Anal. Biochem., 2007, 366, 197-206.

28 S. P. M. Crouch, R. Kozlowski, K. J. Slater and J. Fletcher, The use of ATP bioluminescence as a measure of cell proliferation and cytotoxicity, J. Immunol. Methods, 1993, 160, 81-88.

29 M. Mano, Vinorelbine in the management of breast cancer: New perspectives, revived role in the era of targeted therapy, Cancer Treat. Rev., 2006, 32, 106-118.

30 J. Duy, L. B. Connell, W. Eck, S. D. Collins and R. L. Smith, Preparation of surfactant-stabilized gold nanoparticle-peptide nucleic acid conjugates, J. Nanopart. Res., 2010, 12, 2363-2369.

31 J. G. Kenna, G. N. Major and R. S. Williams, Methods for reducing non-specific antibody binding in enzyme-linked immunosorbent assays, J. Immunol. Methods, 1985, 85, 409-419.

32 N. E. Koval'skaya, N. A. Kuznetsova, O. L. Kaliya, N. S. Gretsova and I. V. Sokolova, The efficiency of the formation of singlet oxygen by a sensitizer based on zinc phthalocyanine, Journal of Applied Spectroscopy, 2001, 68, 287-290.
33 V. Iliev, V. Alexiev and L. Bilyarska, Effect of metal phthalocyanine complex aggregation on the catalytic and photocatalytic oxidation of sulfur containing compounds, J. Mol. Catal. A: Chem., 1999, 137, 1522.

34 M. J. Cook, I. Chambrier, S. J. Cracknell, D. A. Mayes and D. A. Russell, Octa-alkyl zinc phthalocyanines: potential photosensitizers for use in the photodynamic therapy of cancer, Photochem. Photobiol., 1995, 62, 542-545.

35 M. C. Daniel and D. Astruc, Gold nanoparticles: assembly, supramolecular chemistry, quantum-size-related properties, and applications toward biology, catalysis, and nanotechnology, Chem. Rev., 2004, 104, 293-346.

36 G. Schmid, M. Baumle, M. Geerkens, I. Heim, C. Osemann and T. Sawitowski, Current and future applications of nanoclusters, Chem. Soc. Rev., 1999, 28, 179-185.

37 B. D. Chithrani, A. A. Ghazani and W. C. Chan, Determining the size and shape dependence of gold nanoparticle uptake into mammalian cells, Nano Lett., 2006, 6, 662-668.

38 S. Hatz, J. D. C. Lambert and P. R. Ogilby, Measuring the lifetime of singlet oxygen in a single cell: Addressing the issue of cell viability, Photochem. Photobiol. Sci., 2007, 6, 1106-1116.

39 E. Buytaert, M. Dewaele and P. Agostinis, Molecular effectors of multiple cell death pathways initiated by photodynamic therapy, Biochim. Biophys. Acta, Rev. Cancer, 2007, 1776, 86-107.

$40 \mathrm{~N}$. L. Oleinick and I. Belichenko, The role of apoptosis in response to photodynamic therapy: What, where, why, and how, Photochem. Photobiol. Sci., 2002, 1, 1-21.

41 C. Fabris, G. Valduga, G. Miotto, L. Borsetto, G. Jori, S. Garbisa and E. Reddi, Photosensitization with zinc(II) phthalocyanine as a switch in the decision between apoptosis and necrosis, Cancer Res., 2001, 61, $7495-7500$ 